\title{
Causality Between Determinants of Gdp \& Forecasting Using Econometric Modelling - Vecm Approach
}

\author{
Vikram K. Joshi \\ ${ }^{1}$ Assistant Professor - DMT, Shri Ramdeobaba College of \\ Engineering and Management, Nagpur, India
}

\begin{abstract}
The study examines the causality of GDP, exchange rate, inflation and index of industrial production in India over the period 2012:Q1 to 2019:Q4. The causality is examined using the Vector Error Correction Model (VECM). An open source software Gretl is used for analysis of data. The study confirms the existence of unidirectional causality from exchange rate, inflation and industrial production to GDP in the long run. There exists a bidirectional causality between gross domestic product and industrial production, and unidirectional causality between GDP and exchange rate and GDP and inflation in the short run.
\end{abstract}

KEY WORDS: GROSS DOMESTIC PRODUCT, INDEX OF INDUSTRIAL PRODUCTION, EXCHANGE RATE, CONSUMER PRICE INDEX, VECM.

\section{INTRODUCTION}

A high degree of industrialization or increase in the share of manufacturing in GDP is a key feature of modern economic growth. (Kuznets, 1973). In many studies, Index of Industrial Production (IIP) is widely used as a proxy for estimating the current state of GDP as IIP is measured on monthly basis and GDP is measured on quarterly basis in many countries (Sédillot and Pain, 2003). But in most economies, th

e share of services has increased significantly in GDP in recent years and hence raised the question whether the relationship between IIP and GDP is still significant (Fulop and Gyorgy, 2012) or there exists a channel of causation between them and some other variables. Gokmenoglu et al (2015), observed a long-run relationship between

\section{ARTICLE INFORMATION}

Received 15th Oct 2020 Accepted after revision 29th Dec 2020 Print ISSN: 0974-6455 Online ISSN: 2321-4007 CODEN: BBRCBA

Thomson Reuters ISI Web of Science Clarivate Analytics USA and Crossref Indexed Journal

\section{Clarivate
Analytics}

NAAS Journal Score 2020 (4.31)

A Society of Science and Nature Publication,

Bhopal India 2020. All rights reserved.

Online Contents Available at: http//www.bbrc.in/

Doi: http://dx.doi.org/10.21786/bbrc/13.14/81 industrial production, GDP, inflation and Oil price in Turkey. Joshi V. K. (2016) studied the impact of exchange rate, money supply and inflation on index of industrial production in India and found that there exists a bidirectional causality between inflation (WPI) and index of industrial production in the long run and unidirectional causality between index of industrial production and exchange rate and inflation (WPI) and exchange rate.

Razzaque et al (2017) made the empirical assessment of relationship between exchange rate and economic growth and found that depreciation in real exchange rate in Bangladesh led to rise in aggregate output. They asserted that rising inflationary pressure must also be given due consideration. Habib et al (2016) also investigated the relationship between the real exchange rate and economic growth for a panel of 150 countries using five-year average data in the post Bretton Woods period and found the significant relationship between the two in developing countries only. Thus, in the present study attempt is made to study the short run and long run causality between GDP and IIP, ExRate and CPI (inflation) in India and evaluate how IIP, ExRate and CPI impacts the GDP in India and formulate the model of estimation

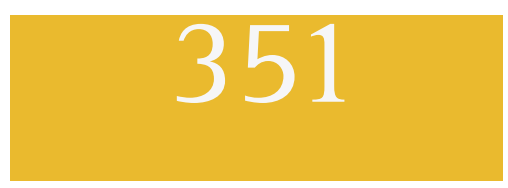


for forecasting GDP with precision. The rest of the paper is organized as below: Section 2 discusses materials and methods, Section 3 deals with results and discussion and section 4 concludes.

\section{MATERIAL AND METHODS}

The present study intends to study the causality between GDP and IIP, ExRate and CPI (inflation) and evaluate whether IIP, ExRate and CPI impacts the GDP in India. The initial model assumption made to begin with the study is given as:

1_GDP $=\alpha_{0}+\alpha_{1} 1 \_$IIPt $+\alpha_{2}$ 1_ExRatet $+\alpha_{3}$ 1_CPIt $+\varepsilon_{t}$

Where, GDP is the gross domestic product (NAS:2011-12), IIP is the index of industrial production (base 2011-12), ExRate is the real exchange rate, and CPI is used as proxy for inflation consumer price index (base 2012) taken from Database on Indian Economy, RBI, India. All the variables are expressed in logarithm as they are growth variables and their corresponding coefficients are the elasticity coefficients associated with them. For the present study, quarterly data from April 2012:Q1 to March 2019:Q4, i.e., 34 quarters is used as the base years were almost the same during this period. The variables, GDP, IIP, ExRate and CPI are selected due to high correlation coefficient between them. Through various literatures the other variables affecting GDP were also identified which includes FDI, FII, money supply, exports, imports, etc. But these variables are highly correlated with some or the other variables which are incorporated in the present study and hence not included in the present study.

To test the stationarity of each series, the Augmented Dickey-Fuller (1979) unit root test is employed. The existence of non-stationarity in levels and stationarity in differences implies the chance of co-integration between the variables and possibility of the long-run relationship between the variables. To investigate the causality between the variables, Johansen's (1988) cointegration approach comprising of two likelihood ratio tests $\left(\lambda_{\text {trace }}\right.$ and $\lambda_{\max }$ ) and Vector Error Correction Model (VECM) (Johansen, 1988) is used which is given as under:

$$
\begin{aligned}
& \mathrm{DXt}=\Sigma \Gamma \mathrm{D} \mathrm{DX}_{\mathrm{t}-\mathrm{i}}+\Pi \mathrm{X}_{\mathrm{t}-1}+\varepsilon_{\mathrm{t}} \\
& \{2\} \quad \varepsilon_{\mathrm{i}, \mathrm{t}} \text { follows } \operatorname{distr}(0, \mathrm{Ht})
\end{aligned}
$$

Where Xt is the $4 \times 1$ vector of 1_GDP, 1_IIP, 1_ExRate and 1 CPI respectively, $D$ is the first difference operator, $\varepsilon_{t}$ is a $4 \times 1$ residual vector indicating $\left(\varepsilon_{\mathrm{GDP}}, \mathrm{t}, \varepsilon_{\mathrm{IIP}}, \mathrm{t}, \varepsilon_{\mathrm{ExRate}}, \mathrm{t}\right.$, $\left.\varepsilon_{\mathrm{CPP}}, \mathrm{t}\right)$ that follows an unspecified conditional distribution with mean zero and time-varying covariance matrix, $\mathrm{Ht}$ . The VECM measurement comprises of an adjustment to changes in Xt in both the short and long-run using the expected parameters $\Gamma_{i}$ and $\Pi$, respectively. The VECM description of the above Equation (2), may be given as follows.

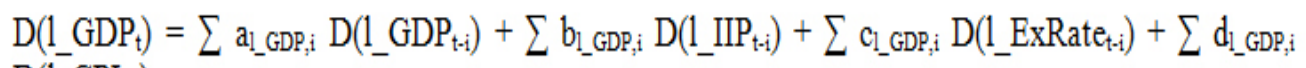

$$
\begin{aligned}
& \mathrm{D}\left(1_{-} \mathrm{CPI}_{\mathrm{t}-\mathrm{i}}\right) \\
& +\mathrm{a}_{1} \mathrm{GDP} \mathrm{Z}_{\mathrm{t}-1}+\varepsilon_{\mathrm{l}_{-} \mathrm{GDP}, \mathrm{t}} \\
& \text {-..-.-. (3) }
\end{aligned}
$$

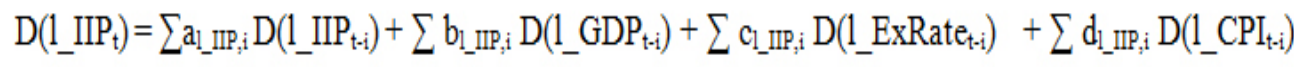

$$
\begin{aligned}
& +\mathrm{a}_{1}\left[\mathrm{IIP} \mathrm{z}_{\mathrm{t}-1}+\varepsilon_{\underline{l} \mathrm{IIP}, \mathrm{t}}\right.
\end{aligned}
$$

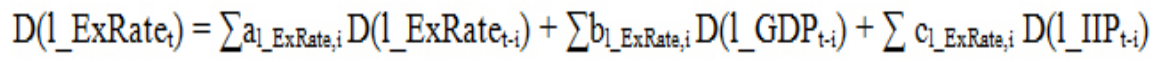

$$
\begin{aligned}
& +\sum d_{1} \text { ExRate, } 1
\end{aligned}
$$

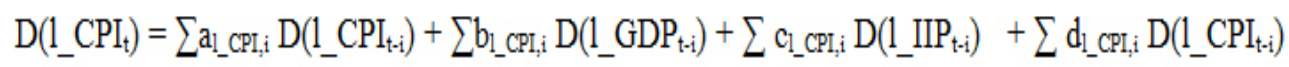

$$
\begin{aligned}
& +a_{l_{-} C P I} Z_{t-1}+\varepsilon_{l_{-} C P I, t}
\end{aligned}
$$

where a's, b's, c's and d's are the coefficients in the short-run, $\mathrm{zt}-1=\beta^{\prime} \mathrm{X}_{\mathrm{t}-1}$ is the error- correction term that captures the impact of deviations of the previous period on the dependent variable from long-run equilibrium perspective in equation (2), and $\varepsilon$ 's indicates the residuals. The Wald test is used to test the hypothesis of short term causality on the joint significance of the lagged estimated coefficients of D(1_GDP $\left.{ }_{\mathrm{t}-\mathrm{i}}\right), \mathrm{D}\left(\mathrm{l}_{-} \mathrm{IIP}_{\mathrm{t}-\mathrm{i}}\right), \mathrm{D}\left(\mathrm{l}_{-}\right.$ExRate $\left._{\mathrm{t}-\mathrm{i}}\right)$, and $\mathrm{D}\left(1 \_\mathrm{CPI} \mathrm{t}-\mathrm{i}_{\mathrm{i}}\right)$.

\section{RESULTS AND DISCUSSIONS}

1. Correlation Estimates: The correlation between the variables taken for the study is shown below in table 1 :

It can be seen that there exists a high and positive correlation between the gross domestic production and other selected variables. Also, there exists high and positive correlation between other variables. The correlation between GDP and IIP is 0.9723 , between GDP and ExRate is 0.8955, between GDP and CPIis 0.9777, 
between IIP and ExRate is 0.8682 , between IIP and CPI is 0.9370 and between ExRate and CPI it is 0.9398.

Table 1. Correlation Matrix
\begin{tabular}{|l|c|c|c|c|}
\hline & 1_GDP & 1_IIP & 1_ExRate & 1_CPI \\
\hline 1_GDP & 1.0000 & 0.9723 & 0.8955 & 0.9777 \\
\hline 1_IIP & & 1.0000 & 0.8681 & 0.9370 \\
\hline 1_ExRate & & & 1.0000 & 0.9398 \\
\hline 1_CPI & & & & 1.0000 \\
\hline
\end{tabular}

Source: Author's computation using Gretl - an open source software.

2. Test for Stationarity: The Augmented Dickey-Fuller test (ADF) is used to test the stationarity of the GDP, IIP, ExRate, and CPI. The Table 2 below shows the results of unit root test for stationarity:
Table 2. Unit Root Test

\begin{tabular}{|c|c|c|c|c|}
\hline \multirow[t]{2}{*}{ Series } & \multicolumn{4}{|c|}{$\begin{array}{l}\text { Augmented Dickey-Fuller } \\
\text { test statistic (with constant \& } 2 \text { lags) }\end{array}$} \\
\hline & Level & p-value & 1st Difference & p-value \\
\hline 1_GDP & -1.42985 & 0.5692 & -6.23969 & $3.108 \mathrm{e}-008$ \\
\hline 1_IIP & -1.33907 & 0.6135 & -8.76135 & $2.597 e-015$ \\
\hline 1_ExRate & -1.75821 & 0.3933 & -4.8963 & $3.312 \mathrm{e}-005$ \\
\hline 1_CPI & -3.28589 & 0.01555 & -- & -- \\
\hline
\end{tabular}

It can be seen that the variables GDP, IIP and ExRate becomes stationary for the first difference and the variable CPI is stationary at level. Hence it is concluded that all the series LogGDP, LogIIP, LogExRate except LogCPI are non-stationary indicating the chances of cointegration between them. This implies that some or all the variables are either integrated with order one I(1) or order two I(2).

\begin{tabular}{|c|c|c|c|c|c|}
\hline Null & Alternativer & $\lambda$ - Trace & p-value & $\lambda-\max$ & p-value \\
\hline None * & 1 & 74.651 & 0.0163 & 38.894 & 0.0006 \\
\hline At most 1 & 2 & 35.757 & 0.0722 & 20.610 & 0.0578 \\
\hline At most 2 & 3 & 15.147 & 0.1079 & 14.920 & 0.0373 \\
\hline At most 3 & 4 & 0.22742 & 0.6710 & 0.22742 & 0.6335 \\
\hline
\end{tabular}

3. Testing for Co-integration: To determine the order of cointegration, the Johansen's cointegration test is applied. The Table 3 below shows the results of $\lambda_{\text {trace }}$ and $\lambda_{\max }$ :

It can be seen that $\lambda_{\text {-trace }}$ and $\lambda_{\text {-max }}$ (eigen statistics) are significant at 5\% level of significance, hence the null hypothesis of no cointegration (none) is rejected. This implies that all the four variables are cointegrated with order 1, which also indicates the possibility of long term causality between them. Thus, a certain variable can be targeted to bring about the desired changes in the other variables in the structure as a policy matter.

4. Vector Error Correction Model Approximation: The existence of cointegration between the variables compels one to use a valid error correction model to capture the short run and long run causality between the variables. (Granger Representation Theorem). The table 4 below gives the summary output of Vector Error Correction Model (VECM):

As seen in table 4, the error correction terms have correct sign in equation 3, 4 and 5, but only first equation's EC term is significant at 1\% level of significance. Thus, the index of industrial production (IIP), exchange rate (ExRate) and inflation (CPI) cause gross domestic product (GDP) in the long run. As error correction terms of other equations are not significant, the channel of causation in the long run cannot be determined. Thus, in the long run, IIP, ExRate and CPI (inflation) cause GDP. To study the direction of causality in the short run Wald test of causality is performed and is shown below in table 5 . As seen in table 5, the index of industrial production exchange rate and inflation cause gross domestic product in the short run in the equation of GDP. In the short run, the GDP cause IIP, but the exchange rate and inflation does not cause IIP. 
Table 4. Estimated VECM with 4 lags

\begin{tabular}{|c|c|c|c|c|}
\hline Equation & D(1_GDP)) & D(1_IIP) & D(1_ExRate) & D(1_CPI) \\
\hline \multirow[t]{3}{*}{$\mathrm{EC}$} & $-0.139145^{* * *}$ & -0.00788852 & -0.00292710 & 0.0344160 \\
\hline & {$[-5.005]$} & {$[-0.07905]$} & {$[-0.02672]$} & {$[0.6144]$} \\
\hline & $(0.0002)$ & $(0.9381)$ & $(0.9791)$ & $(0.5488)$ \\
\hline \multirow[t]{3}{*}{$\mathrm{C}$} & $1.39878^{* * * *}$ & 0.0458866 & 0.0201588 & -0.332395 \\
\hline & [5.053] & {$[0.04618]$} & [0.01848] & {$[-0.5960]$} \\
\hline & $(0.0002)$ & $(0.9638)$ & $(0.9855)$ & $(0.5607)$ \\
\hline \multirow{3}{*}{ D(1_GDP(-1)) } & -0.249929 & $1.70828^{* * *}$ & -0.815937 & -0.419838 \\
\hline & {$[-1.454]$} & [0.617203] & {$[-1.204]$} & {$[-1.212]$} \\
\hline & $(0.1681)$ & $(0.0151)$ & $(0.2485)$ & $(0.2456)$ \\
\hline \multirow[t]{3}{*}{ D(1_GDP(-2)) } & $-0.540413^{* * *}$ & -0.0707112 & $0.962512^{* * *}$ & 0.158903 \\
\hline & {$[-5.098]$} & {$[-0.1858]$} & [2.304] & [0.7439] \\
\hline & $(0.0002)$ & $(0.8553)$ & $(0.0371)$ & $(0.4692)$ \\
\hline \multirow[t]{3}{*}{ D(1_GDP(-3)) } & 0.00309917 & $1.40301^{* * * *}$ & 0.249705 & 0.0697622 \\
\hline & [0.02695] & [3.399] & {$[0.5510]$} & [0.3011] \\
\hline & $(0.9789)$ & $(0.0043)$ & $(0.5903)$ & $(0.7678)$ \\
\hline \multirow[t]{3}{*}{ D(1_IIP(-1)) } & $0.475580^{* * *}$ & -0.449858 & -0.0700679 & -0.0483200 \\
\hline & [6.581] & {$[-1.734]$} & {$[-0.2460]$} & {$[-0.3319]$} \\
\hline & $(1.23 e-05)$ & $(0.1048)$ & $(0.8092)$ & $(0.7449)$ \\
\hline \multirow[t]{3}{*}{ D(1_IIP(-2)) } & $0.202831^{* * *}$ & $-0.760343^{* *}$ & 0.300739 & 0.140295 \\
\hline & [2.351] & {$[-2.456]$} & [0.8846] & [0.8072] \\
\hline & (0.0339) & $(0.0277)$ & $(0.3913)$ & $(0.4331)$ \\
\hline \multirow[t]{3}{*}{ D(1_IIP(-3)) } & $0.132972^{* *}$ & $-0.307204^{*}$ & 0.00844564 & 0.0504368 \\
\hline & [2.763] & {$[-1.778]$} & [0.04453] & [0.5202] \\
\hline & $(0.0152)$ & $(0.0970)$ & $(0.9651)$ & $(0.6111)$ \\
\hline \multirow[t]{3}{*}{ D(1_ExRate(-1)) } & $0.148963^{* * *}$ & 0.0512926 & 0.183883 & -0.0500705 \\
\hline & [3.150] & {$[0.3022]$} & {$[0.9867]$} & {$[-0.5255]$} \\
\hline & $(0.0071)$ & $(0.7670)$ & $(0.3406)$ & $(0.6075)$ \\
\hline \multirow[t]{3}{*}{ D(1_ExRate(-2)) } & -0.00529211 & -0.0536639 & 0.315503 & 0.0141766 \\
\hline & {$[-0.1104]$} & {$[-0.3118]$} & [1.670] & {$[0.1467]$} \\
\hline & $(0.9137)$ & $(0.7598)$ & $(0.1172)$ & $(0.8854)$ \\
\hline \multirow[t]{3}{*}{ D(1_ExRate(-3)) } & 0.0677562 & 0.146576 & $-0.527285^{* * *}$ & -0.0448219 \\
\hline & [1.534] & [0.9245] & {$[-3.029]$} & {$[-0.5036]$} \\
\hline & $(0.1473)$ & $(0.3709)$ & $(0.0090)$ & $(0.6224)$ \\
\hline \multirow[t]{3}{*}{ D(1_CPI(-1)) } & $-0.197480^{* *}$ & -0.243529 & 0.396637 & 0.301474 \\
\hline & {$[-2.249]$} & {$[-0.7726]$} & {$[1.146]$} & {$[1.704]$} \\
\hline & $(0.0412)$ & $(0.4526)$ & $(0.2710)$ & $(0.1105)$ \\
\hline \multirow[t]{3}{*}{ D(1_CPI(-2)) } & -0.127645 & $0.796092^{* * *}$ & 0.423831 & -0.0911207 \\
\hline & {$[-1.293]$} & [2.246] & [1.089] & {$[-0.4579]$} \\
\hline & $(0.2171)$ & $(0.0414)$ & $(0.2945)$ & $(0.6540)$ \\
\hline \multirow[t]{3}{*}{ D(1_CPI(-3)) } & $-0.196716^{*}$ & -0.412177 & -0.151381 & 0.347744 \\
\hline & {$[-1.789]$} & {$[-1.044]$} & {$[-0.3493]$} & [1.569] \\
\hline & $(0.0953)$ & $(0.3141)$ & $(0.7321)$ & $(0.1389)$ \\
\hline R2 & 0.950139 & 0.863042 & 0.797860 & 0.726765 \\
\hline Durbin-Watson & 1.794869 & 1.500998 & 2.352640 & 1.691355 \\
\hline
\end{tabular}

[ ] - indicates t -ratio. ( ) - indicates $p$ - value.

* signifies $10 \%$ level of significance. ${ }^{* *}$ signifies $5 \%$ level of significance.

*** signifies $1 \%$ level of significance.

Source: Author's computation using Gretl - an open source software. 
Table 5. Wald Test F-Statistics with 4 lags

\begin{tabular}{|c|c|c|c|c|}
\hline & D(1_GDP)) $\downarrow$ & D(1_IIP) $\downarrow$ & D(1_ExRate) $\downarrow$ & $\mathrm{D}\left(1 \_\mathrm{CPI}\right) \downarrow$ \\
\hline D(1_GDP)) & -- & 3.6014 & & \\
\hline [0.0412] & 2.3201 & & & \\
\hline [0.1216] & 2.0462 & & & \\
\hline \multicolumn{5}{|l|}{ [0.1570] } \\
\hline D(1_IIP) & 8.9879 [0.0018] & -- & 0.37486 & \\
\hline [0.8219] & 1.2227 & & & \\
\hline \multicolumn{5}{|l|}{$[0.3561]$} \\
\hline D(l_ExRate) & $2.7111[0.0857]$ & 1.0233 & & \\
\hline$[0.4374]$ & -- & 0.11300 [0.9753] & & \\
\hline D(1_CPI) & $3.4123[0.0478]$ & 2.0785 & & \\
\hline [0.1523] & 0.74807 & & & \\
\hline$[0.5794]$ & -- & & & \\
\hline
\end{tabular}

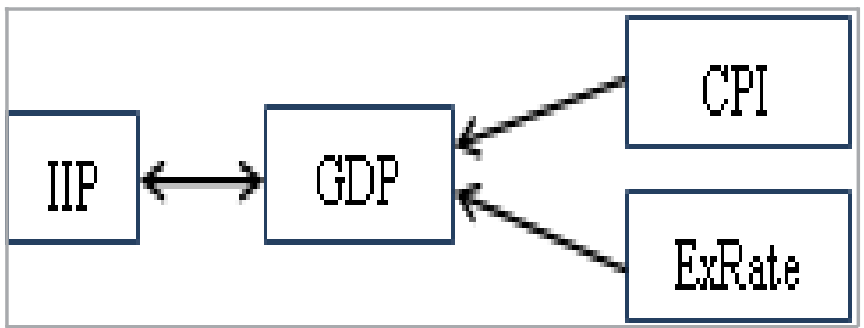

\begin{tabular}{|l|c|c|c|c|c|c|}
\hline $\begin{array}{l}\text { Year/ } \\
\text { Quarter }\end{array}$ & L_GDP & Forecast & $\begin{array}{c}\text { Quarter } \\
\text { Year/ }\end{array}$ & L_GDP & Forecast & \\
\hline $2016: 2$ & 14.842266 & 14.842525 & $2019: 1$ & 15.011766 & 15.012587 & \\
\hline $2016: 3$ & 14.857769 & 14.857037 & $2019: 2$ & 15.002788 & 15.004303 & \\
\hline $2016: 4$ & 14.880894 & 14.881234 & $2019: 3$ & 15.014939 & 15.016519 & \\
\hline $2017: 1$ & 14.898060 & 14.903365 & $2019: 4$ & 15.038418 & 15.043095 & \\
\hline $2017: 2$ & 14.901575 & 14.892017 & & Forecast & Std Error & $95 \%$ Interval \\
\hline $2017: 3$ & 14.926110 & 14.920203 & $2020: 1$ & 15.056696 & 0.003356 & $15.050119-15.063273$ \\
\hline $2017: 4$ & 14.954449 & 14.950215 & $2020: 2$ & 15.071127 & 0.005449 & $15.060448-15.081806$ \\
\hline $2018: 1$ & 14.965249 & 14.968539 & $2020: 3$ & 15.091744 & 0.006363 & $15.079272-15.104215$ \\
\hline $2018: 2$ & 14.960379 & 14.961627 & $2020: 4$ & 15.117697 & 0.008750 & $15.100547-15.134847$ \\
\hline $2018: 3$ & 14.980823 & 14.983265 & $2021: 1$ & 15.135309 & 0.010554 & $15.114623-15.155994$ \\
\hline $2018: 4$ & 15.008465 & 15.005310 & $2021: 2$ & 15.146562 & 0.012155 & $15.122737-15.170386$ \\
\hline
\end{tabular}

Source: Author's computation using Gretl - an open source software.

Thus, in the short run, it seems that there exists bidirectional causality between GDP and IIP. The exchange rate equation shows that, the GDP, IIP and inflation doesn't cause exchange rate in the short run. Similarly, in the last equation of inflation, no variable (the GDP, index of industrial production and exchange rate) cause inflation in the short run. Thus, there exists a bidirectional causality between GDP and IIP, and unidirectional causality between CPI \&t GDP and ExRate \&t GDP. Thus, CPI causes GDP and ExRate causes GDP in the short run and is summarized as below:

To validate the model, the predicted values are obtained for the some sample data values and out of the sample period. The results are presented as below: From the above table, it can be seen that VECM predicts the GDP 
with very low deviation and out of sample forecasts also seems to be reliable as the standard error is very low. Thus, under the conditions of non-stationary and cointegrating series, VECM is considered as the most appropriate model which not only predicts, but shows the causality effect as well.

\section{CONCLUSION}

The study shows the existence of long run unidirectional causality between exchange rate, industrial production and inflation towards gross domestic production and short run bidirectional causality between industrial production and gross domestic product and unidirectional causality between exchange rate and GDP \& inflation and GDP towards GDP in India. This confirms with the study by Mlambo, 2020 according to which exchange rate and inflation significantly impacts manufacturing sector in SACU (South African Custom Union) countries. The present study shows the bidirectional causality between industrial production and GDP in the short run in India. Also the VECM model effectively captured the long run causality of industrial production, exchange rate and inflation for forecasting GDP in India.

From the policy perspective, the monetary policy of India is inflation-targetting rather than growth targeting. But the short run and long run economic growth perspective cannot be ignored. Looking at the present state of economic growth it is the need of an hour to look towards economic growth targets so that economic development becomes more prominent. The exchange rate volatility directly affects the exports and imports of the country and inflation determines the buying capacity of the market, and hence are very important from the perspective of industrial output and aggregate output of the market. Thus, at planned level of inflation and exchange rate, VECM model can give the direction of
GDP achievable in near future to the policy makers.

\section{REFERENCES}

Dickey, D. A. and Fuller, W. A. (1979) Distribution of the estimates for autoregressive time series with a unit root, Journal of American Statistical Association, 74(366), 427- 431.

Fulop Gabor and Gyomai Gyorgy (2012), Transition of the OECD CLI System to a GDP-Based Business Cycle Target, Report on OECD Composite Leading Indicators, OECD.

Gokmenoglua Korhan, Azina Vahid, Taspinara Nigar (2015), The Relationship between Industrial Production, GDP, Inflation and Oil Price: The Case of Turkey, Procedia Economics and Finance 25 ( 2015 ) 497 503.

Habib Maurizio Michael, Mileva Elitza, Stracca Livio (2016), The Real Exchange Rate and Economic Growth: Revisiting the Case Using External Instruments, ECB Working Paper No. 1921.

Joshi Vikram K (2016), Impact of Exchange rate, Inflation \& Money Supply on Industrial Production in India 2005 - 2015, SuGyaan, Management Journal of Siva Sivani Institute of Management, Vol VIII, Issue-I, Jan-June, pn 3-12.

Johansen, S. (1988) Statistical Analysis and Cointegrating Vectors, Journal of Economic Dynamics and Control, 12(2-3), 231-254.

Kuznets Simon (1973), Modern Economic Growth: Findings and Reflections, The American Economic Review, Vol. 63, No. 3, June, pp. 247-258.

Razzaque Mohammad A., Bidisha Sayema Haque, Khondker Bazlul Haque (2017), Exchange Rate and Economic Growth: An Empirical Assessment for Bangladesh, Journal of South Asian Development, 12(1), 42-64.

Mlambo Courage (2020), Exchange rate and manufacturing sector performance in SACU states, Cogent Business \& Management, 7: 1787735, 1-16. 